Original Research Paper

\title{
Penggunaan LKM untuk Menunjang Kegiatan Laboratorium Virtual Fisika Inti
}

\author{
Hidayati $^{1 *}$, Masril $^{2}$ \\ ${ }^{1}$ Jurusan Fisika Fakultas MIPA, Universitas Negeri Padang, Indonesia.
}

\author{
Article history \\ Received: February $21^{\text {th }} 2019$ \\ Revised: April $19^{\text {th }} 2019$ \\ Accepted: April 22 2019 \\ *Hidayati: Jurusan Fisika \\ Fakultas MIPA, Universitas \\ Negeri Padang, Indonesia; \\ Email: \\ hidayati@fmipa.unp.ac.id
}

\begin{abstract}
To improve the quality of the Nuclear Physics lectures in addition to understanding the material as a knowledge aspect, students are also expected to practice for the skills. The Nuclear Physics lecture material is microscopic so it requires laboratory activities, but there are no suitable practical tools available in the laboratory of The Physics Department, mathematics and science faculty, Padang university. Therefore, a virtual laboratory model was developed in this research which was supported by students' worksheets. The valid and practical students' worksheet has been obtained. Then, it was tried out to students who take the Nuclear physics lecture to see whether the students' worksheets are effective to support virtual laboratory activities. The research conducted is included in the type of quasi-experimental research. The population is students who take part in the Nuclear Physics lecture in semester January-June 2018. The samples were taken using Cluster Random Sampling techniques. Data on knowledge and skill competencies were analyzed using the t-test at a real level of 0.05 . Based on the results of data analysis, there were significant differences in the two sample classes. The results of the regression analysis indicate that there is a strong correlation between the use of students' worksheet to support virtual laboratory activities for knowledge and skills competencies.
\end{abstract}

Key Words: Nuclear Physics; Students Worksheet; Virtual Laboratory

Abstrak: Untuk meningkatkan mutu perkuliahan Fisika Inti disamping memahami materi dari aspek pengetahuan diharapkan mahasiswa juga melakukan pratikum untuk aspek keterampilan. Materi perkuliahan Fisika Inti ini bersifat mikroskopik sehingga membutuhkan kegiatan dilaboratorium, namun sampai saat ini belum ada alat pratikum yang sesuai tersedia di laboratorium Jurusan Fisika FMIPA UNP. Untuk itu melalui penelitian ini dikembangkan model laboratorium virtual yang ditunjang dengan LKM. Telah didapatkan LKM yang valid dan praktis. Untuk melihat apakah LKM untuk menunjang kegiatan laboratorium virtual ini efektif atau tidak dicobakan kepada mahasiswa yang mengikuti perkuliahan Fisika Inti Penelitian yang dilakukan termasuk dalam jenis penelitian kuasi eksperimen. Populasi mahasiswa jurusan Fisika yang mengikuti perkuliahan Fisika Inti semester Januari-Juni 2018. Sampel diambil menggunakan teknik Cluster Random Sampling. Data berupa nilai pada kompetensi pengetahuan dan keterampilan dianalisis menggunakan tes-t pada tingkat nyata 0.05 . Berdasarkan hasil analisis data, ada perbedaan yang signifikan dalam kedua kelas sampel. Hasil analisis menunjukkan bahwa ada pengaruh penggunaan LKM untuk menunjang kegiatan laboratorium virtual dengan kompetensi pengetahuan dan keterampilan mahasiswa.

Kata kunci: Fisika Inti; LKM; Laboratorium Virtual 


\section{Pendahuluan}

Matakuliah fisika inti merupakan matakuliah wajib dalam kurikulum Jurusan Fisika FMIPA UNP. Matakuliah ini diambil oleh seluruh mahasiswa Jurusan Fisika pada Semester 6 dengan tujuan agar mahasiswa dapat memahami konsepkonsep fisika lanjut. Berbagai upaya telah dilakukan untuk menunjang pelaksanaan perkuliahan Fisika Inti. Pada perkuliahan fisika inti keaktifan dan nilai akhir yang diperoleh mahasiswa sudah meningkat dari tahun ke tahunnya, tapi belum seperti yang diharapkan. Masih banyak mahasiswa yang belum mampu mencapai hasil yang memuaskan. Hal ini mungkin karena selama ini yang menjadi perhatian baru dari segi proses dan hasil untuk aspek pengetahuan sedangkan pratikumnya belum mendapat perhatian.

Bila dilihat dari segi sarana dan prasarana perkuliahan, fasilitas internet sudah sangat luas dan mudah di akses di UNP. Fasilitas ini sudah digunakan dalam perkuliahan Fisika Inti dalam bentuk e-learning. Fasilitas internet dan e-learning ini masih digunakan dalam kompetensi pengetahuan. Fasilitas e-learning digunakan untuk memberikan bahan perkuliahan dan juga tugas pada mahasiswa dan mahasiswa menyerahkan tugas. Hal ini karena belum tersedianya perangkat penunjang dalam melakukan kegiatan perkulihan fisika inti pada kompetensi keterampilan. Oleh sebab itu dalam rangka meningkatkan mutu perkuliahan Fisika Inti disamping memahami materi dari aspek pengetahuan diharapkan mahasiswa juga melakukan pratikum untuk peningkatan aspek keterampilan. Materi dari perkuliahan Fisika Inti ini bersifat mikroskopik sehingga sampai saat ini belum ada alat pratikum yang tersedia di laboratorium Jurusan Fisika FMIPA UNP. Belum adanya alat pratikum fisika inti ini disebabkan biaya yang besar untuk pengadaan dan juga memerlukan penanganan yang khusus dari segi keamanan dan keselamatan. Menurut Fahruddin (2016) Kemampuan akademik berpengaruh signifikan terhadap hasil belajar kognitif mahasiswa. Untuk itu pendidik harus memilih metode pembelajaran yang tepat agar dapat meningkatkan hasil belajar kognitif mahasiswa

Untuk mengatasi kendala dalam kegiatan praktikum dapat dilakukan dengan berbagai cara, diantaranya adalah dengan pemanfaatan Teknologi Informasi dan Komunikasi (TIK), yang ditunjang dengan penggunaan komputer sebagai perangkat TIK, misalnya eksperimen semu (virtual laboratory). Meskipun virtual laboratory bukan kegiatan yang sesungguhnya, tetapi mahasiswa dapat melakukan praktikum seperti praktikum sesungguhnya. Virtual laboratory merupakan salah satu proses pembelajaran berbasis ICT yang dapat dijadikan sebagai solusi alternatif pembelajaran dengan metode praktikum. Laboratorium virtual ini sudah banyak dikembangkan, Contoh yang sudah banyak digunakan adalah yang dikembangkan oleh University of Colorado yaitu Physics Education Technology (PhET). Didalam PhET terdapat simulasi yang bersifat teori dan percobaan yang melibatkan pengguna secara aktif. Pengguna dapat memanipulasi kegiatan-kegiatan yang berkaitan dengan eksperimen. Sehingga selain dapat membangun konsep, PhET juga dapat digunakan untuk memunculkan keterampilan proses sains.

Menurut Clark (2014) memaparkan keberhasilan dari kegiatan praktikum menggunakan aplikasi PhET. Kegiatan laboratorium virtual menggunakan PhET membimbing siswa melalui perbandingan dan analisis dari enam model atom yang disajikan dalam simulasi, yang memberikan representasi visual dari konsep abstrak. Kegiatan laboratorium virtual membahas topik sains yang penting dan menantang dan menawarkan wawasan siswa ke dalam sifat sains. Hasil survei penelitian menunjukkan respon positif dari siswa untuk kegiatan laboratorium virtual. Adams (2010) menemukan bukti bahwa simulasi interaktif PhET dapat menjadi alat yang kuat untuk mencapai pembelajaran sains. Simulasi PhET membantu siswa membangun pemahaman konseptual sains. Menurut Moore (2014) Simulasi PhET simulasi komputer interaktif muncul sebagai alat yang sangat kuat untuk mendukung pembelajaran kimia. Khairunnisak (2018) menyatakan PhET lebih memudahkan guru maupun peserta didik dalam proses pembelajaran, sehingga bisa menumbuhkan motivasi terhadap peserta didik dan meningkatkan pemahaman konsep siswa. Simulasi PhET tepat diterapkan di sekolah-sekolah yang tidak mempunyai fasilitas laboratorium sehingga bisa membantu para guru dalam mengajar.

Simulasi Interaktif PhET yang

dikembangkan University of Colorado Boulder menyediakan akses yang dinamis dan merepresen tasikan hal yang tak terlihat menjadi dapat terlihat, membuat penyelidikan menyenangkan bagi siswa. Keuntungan yang ditawarkan oleh simulasi PhET, yaitu dapat di akses di unduh secara bebas dan tanpa berbayar pada situs http://PhET.colorado.edu. serta dapat digunakan tanpa terkoneksi dengan internet (offline). Adanya program PhET ini memungkinkan dapat digunakan untuk praktikum virtual Fisika Inti yang dilengkapi dengan LKM sesuai dengan 
Capaian Pembelajaran yang ada. LKM sebagai salah satu bahan ajar dalam perkuliahan dapat sebagai alternatif dalam memotivasi mahasiswa untuk mencapai tujuannya (Susilawati, 2015)

Laboratorium Virtual memiliki banyak jenis, baik fungsi, fitur, dan kelengkapan fasilitas disesuaikan kebutuhan, khususnya sesuai materi yang akan dipraktikumkan. Banyak materi-materi fisika yang tidak bisa dipraktikumkan karena bersifat abstrak dan komplek, sehingga diperlukan visualisasi dan simulasi melalui laboratorium virtual.

Praktikum virtual atau kegiatan laboratorium virtual memungkinkan untuk mengatasi alat dan bahan praktikum yang mahal dan berbahaya. Kegiatan laboratorium virtual dapat memfasilitasi mahasiswa untuk bekerja sesuai dengan metode ilmiah, membantu mahasiswa berpikir kritis, membuat waktu belajar lebih efisien, membantu mahasiswa belajar mandiri, dan dapat digunakan untuk mengukur penguasaan materi pembelajaran mahasiswa (Masril, 2018). Disamping itu melalui aktivitas laboratorium mahasiswa dapat mengembangkan ketrampilan akademik dan sosial. Dari sudut pandang sosial, mahasiswa akan mudah menghargai pendapat orang lain, belajar untuk mengomunikasikan ide, dan bekerja bersama dalam tim (Gunawan G. A., 2017).

Menurut Babateen (2011) laboratorium virtual dapat didefinisikan sebagai lingkungan pembelajaran virtual yang menstimulasikan laboratorium pada komputer dengan menyediakan alat, maerial, atau suatu set alat laboratorium untuk melakukan percobaan secara individu maupun kelompok dalam bentuk online maupun offline

Menurut Chaurura dan Chuma (2015) kelebihan dari laboratorium virtual antara lain; (a) meningkatkan aksesibilitas untuk pelaksanaan kegiatan laboratorium yang terkendala jarak secara geografis dan kontak fisik secara langsung dengan objek; (b) pelaksanaan kegiatan laboratorium virtual lebih aman dibandingkan kegiatan laboratorium nyata; (c) menjadi bekal dalam melatih siswa untuk pelaksanaan percobaan baru yang belum pernah dilakukan dan berisiko tinggi dalam hal keamanan; (d) laboratorium virtual tidak dibatasi oleh kebutuhan akan ruang seperti pada laboratorium nyata; (e) pengadaan dan pemeliharaan relatif lebih murah; (f) mengurangi prosedur yang kompleks yang biasa ditemukan pada kegiatan laboratorium nyata; dan (g) meningkatkan motivasi siswa.

Penelitian Masril (2019) mendapatkan bahwa terdapat pengaruh yang berarti penggunaan model pembelajaran discovery berbantuan virtual lab terhadap pencapaian ketiga kompetensi yaitu kompetensi sikap, pengetahuan

Prastowo (2011) mengungkapkan bahwa Lembar Kerja Siswa/Mahasiswa terdiri dari beberapa lembaran yang berisi kegiatan siswa agar siswa dapat melakukan kegiatan real dalam berbagai persoalan yang dipelajari. Hal ini menunjukkan bahwa untuk mengembangakan aktivitas mahasiswa harus difasilitasi dan didukung dengan bahan belajar mahasiswa yang berisi suatu kegiatan yang membuat mahasiswa bernalar dan berpikir dalam memecahkan suatu masalah.

Untuk itu dilihat pengaruh penggunaan LKM untuk menunjang kegiatan Laboratorium virtual terhadap pencapaian kompetensi mahasiswa pada mata kuliah Fisika Inti

\section{Metode}

Penelitian ini menggunakan penelitian Quasi Eksperimental Design. Metode ini digunakan agar dapat mengatasi ketidakmampuan peneliti dalam mengkondisikan variabel luar yang berpengaruh terhadap penelitian (Sugiyono, 2012). Penggunaan Quasi Eksperimental Design ini peneliti lebih mudah untuk mengetahui apakah ada atau tidak pengaruh dari hal yang diberikan kepada subjek yang diselidiki. Langkahnya yaitu membandingkan antara kedua kelas sampel. Pada kelas eksperimen diberi LKM untuk memandu pratikum virtual dan dikelas kontrol tidak menggunakan LKM tapi menggunakan worksheet yang sudah ada pada tahun sebelumnya.

Rancangan penelitian ialah posttest only control grup design. Disain dari penelitian ini disajikan seperti Tabel 1.

Tabel 1. Rancangan post test only control grup design

\begin{tabular}{lll}
\hline Kelas & Perlakuan & Post test \\
\hline Eksperimen & $\mathrm{X}$ & $\mathrm{T}_{1}$ \\
Kontrol & - & $\mathrm{T}_{2}$ \\
\hline
\end{tabular}

Pada rancangan ini $\mathrm{X}$ adalah perlakuan pada kelas eksperimen yaitu penggunaan LKM Laboratorium Virtual, $\mathrm{T}_{1}$ adalah tes akhir untuk kelas eksperimen dan $T_{2}$ tes akhir untuk kelas kontrol.

Populasi dari penelitian ini yaitu semua kelas di Jurusan Fisika yang mengikuti perkuliahan Fisika Inti semester Januari-Juni 2018. Sampel diambil menggunakan teknik Cluster Sampling. Penelitian ini variabel bebasnya ialah penggunaan penggunaan LKM untuk menunjang kegiatan 
Laboratorium virtual pada perkuliahan mata kuliah Fisika Inti Fisika Inti. Variabel pencapaian kompetensi fisika inti menjadi variabel terikat. Serta variabel kontrol adalah: materi perkuliahan sama, kemampuan awal mahasiswa kedua kelas sama, bentuk evaluasi post test yang diujikan ke kedua kelas sama.

Selanjutnya nilai yang diambil untuk penelitian melalui format penilaian aspek sikap berupa lembar observasi selama proses kegiatan perkuliahan berlangsung, dan hasil belajar aspek pengetahuan diperoleh dari hasil ujian tertulis diakhir proses perkuliahan, dimana pada penelitian ini nilai hasil belajar pada aspek pengetahuan diperoleh posttes kemudian nilai hasil proses perkuliahan aspek keterampilan diperoleh dengan format observasi dan dilengkapi dengan rubric penskoran penilaian kinerja. Data-data dalam penelitian ini adalah hasil penilaian dari ketiga aspek penilaian. Kedua aspek penilaian dalam penelitian ini adalah aspek pengetahuan, dan keterampilan. Aspek penilaian ini diolah dengan pengolahan data statistik hingga akhirnya didapatkan jawaban atas hipotesis penelitian. Teknik analisis data yang digunakan dalam penelitian yaitu analisis statistik deskriptif, dan uji perbandingan.

\section{Hasil dan Pembahasan}

Nilai hasil belajar yang didapat pada penelitian ini yaitu berbentuk nilai kompetensi pengetahuan, dan keterampilan mahasiswa. Data penilaian kompetensi pengetahuan didapat dengan cara melakukan ujian di akhir proses perkuliahan. Penilaian dilakukan dengan cara memberikan post test dalam bentuk soal pilihan ganda 25 butir soal di kelas kontrol dan kelas eksperimen. Dari hasil tes akhir yang telah diberikan diperoleh sebaran data untuk kelas kontrol dan kelas eksperimen pada kompetensi pengetahuan yang disajikan seperti Tabel 2.

Tabel 2. Sebaran Data Kedua Kelas Sampel pada Kompetensi Pengetahuan

\begin{tabular}{lllll}
\hline \multirow{2}{*}{$\begin{array}{l}\text { Interval } \\
\text { Nilai }\end{array}$} & \multicolumn{2}{l}{ Kelas } & \multicolumn{3}{l}{ Eksperimen } & $\begin{array}{l}\text { Kelas } \\
\text { Kontrol }\end{array}$ \\
\cline { 2 - 5 } & Jumlah & $\%$ & Jumlah & $\%$ \\
\hline $41-60$ & 9,0 & 20,9 & 8,0 & 25,8 \\
$61-80$ & 24 & 55,8 & 19 & 61,3 \\
$81-100$ & 10 & 23,3 & 4,0 & 12,9 \\
jumlah & 43 & 100,0 & 31 & 100,0 \\
\hline
\end{tabular}

Tabel 2 menunjukkan bahwa persentase data kompetensi pengetahuan mahasiswa dengan katogori amat baik pada rentang 81-100 untuk kelas eksperimen yaitu 23,3\% sedangkan pada kelas kontrol yaitu $12,9 \%$.

Hasil uji normalitas diperoleh bahwa nilai post test masing-masing kelas sampel terdistribusi normal. Dan dari uji homogenitas pada kelas sampel, diperoleh bahwa kedua kelas sampel homogen. Berikutnya dilakukan uji-t. Hasil uji-t dapat diketahui dari Tabel 3.

Tabel 3. Hasil analisis uji-t pada Kompetensi Pengetahuan

\begin{tabular}{lccccc}
\hline Kelas & $\mathrm{N}$ & & $\mathrm{S}^{2}$ & $\mathrm{t}_{\mathrm{h}}$ & $\mathrm{t}_{\mathrm{t}}$ \\
\hline Eksperimen & 43 & 72,06 & 65,04 & 0,56 & 2.00 \\
Kontrol & 31 & 71.04 & 50,58 & 0,56 & \\
\hline
\end{tabular}

Tabel 3 menunjukkan bahwa $t_{\text {hitung }}$ sebesar 0,56 sedangkan $t_{\text {tabel }} 2,00$, sehingga hipotesis kerja Hi berbunyi "terdapat pengaruh yang berarti penggunaan LKM laboratorium virtual fisika inti dengan kompetensi pengetahuan mahasiswa" pada taraf nyata 0,05 dapat diterima. Berarti terdapat pengaruh penggunaan LKM laboratorium virtual fisika inti terhadap pencapaian kompetensi pengetahuan mahasiswa.

Untuk data penilaian kompetensi keterampilan didapat dengan cara mengisi unjuk kerja selama proses perkuliahan di kelas kontrol dan kelas eksperimen. Dari unjuk kerja diperoleh sebaran data untuk kelas kontrol dan kelas eksperimen pada kompetensi keterampilan yang disajikan seperti Tabel 4.

Tabel 4. Sebaran Data Kedua Kelas Sampel Pada Kompetensi Keterampilan

\begin{tabular}{lllll}
\hline \multirow{2}{*}{$\begin{array}{l}\text { Interval } \\
\text { Nilai }\end{array}$} & \multicolumn{2}{l}{ Kelas } & \multicolumn{3}{l}{ Eksperimen } & $\begin{array}{l}\text { Kelas } \\
\text { Kontrol }\end{array}$ \\
\cline { 2 - 5 } & Jumlah & $\%$ & Jumlah & $\%$ \\
\hline $41-60$ & 9 & 20,93 & 9 & 29,03 \\
$61-80$ & 22 & 51,16 & 17 & 54,84 \\
$81-100$ & 12 & 27,91 & 5 & 16,13 \\
jumlah & 43 & 100,00 & 31 & 100,00 \\
\hline
\end{tabular}

Tabel 4 menunjukkan bahwa persentase data kompetensi keterampilan mahasiswa dengan katogori amat baik pada rentang 81-100 untuk kelas eksperimen yaitu $27,91 \%$ sedangkan pada kelas kontrol yaitu $16,13 \%$.

Hasil uji normalitas dan uji homogenitas menunjukkan bahwa masing-masing kelas terdistribusi normal serta kedua kelas homogen. Selanjutnya dari hasil uji $\mathrm{t}$ dapat diketahui dari Tabel 5. 
Tabel 5. Hasil Analisis Uji t Pada Kompetensi Keterampilan

\begin{tabular}{llllll}
\hline Kelas & $\mathrm{N}$ & $x$ & $\mathrm{~S}^{2}$ & $\mathrm{t}_{\mathrm{h}}$ & $\mathrm{t}_{\mathrm{t}}$ \\
\hline Eksperimen & 42 & 75,03 & 93,50 & \multirow{2}{*}{2.83} & 2.00 \\
Kontrol & 31 & 68,50 & 416,10 & & \\
\hline
\end{tabular}

Tabel 5 menunjukkan bahwa $t_{\mathrm{h}}$ bernilai 2,83 sedangkan $\mathrm{t}_{\text {tabel }} 2,00$, sehingga hipotesis kerja Hi berbunyi "terdapat pengaruh yang berarti penggunaan LKM laboratorium virtual fisika inti dengan kompetensi keterampilan mahasiswa" pada taraf nyata 0,05 dapat diterima. Berarti terdapat pengaruh penggunaan LKM laboratorium virtual fisika inti terhadap pencapaian kompetensi keterampilan mahasiswa.

\section{Kesimpulan}

Berdasarkan hasil penelitian dapat ditarik kesimpulan, yaitu terdapat pengaruh penggunaan Lembar Kerja Mahasiswa (LKM) laboratorium virtual fisika inti terhadap pencapaian kompetensi pengetahuan dan kompetensi keterampilan Fisika Inti mahasiswa.

\section{Ucapan Terima Kasih}

Terima kasih kepada Lembaga Penelitian dan Pengabdian pada Masyarakat UNP yang telah mendanai penelitian ini dalam bentuk Penelitian Produk Terapan (PPT). PPT ini dengan dibiayai oleh: DIPA (Daftar Isian Pelaksana Anggaran) UNP Nomor SP DIPA-042.01.2.400929/2018 tanggal 5 Desember 2017 sesuai dengan Surat Perjanjian Pelaksanaan Penelitian Produk Terapan Tahun Anggaran 2018; Nomor: Nomor: 1354/UN35.2/PG/2018 tanggal 16 April 2018.

\section{Daftar Pustaka}

Adams, W.K. 2010. Student engagement and learning with PhET interactive simulations. Il Nuovo Cimento, 1 (1). 1-12. doi. http://10.1393/ncc/i2010-10623-0

Babateen H.M. 2011. The Role of Virtual Laboratories in Science Education. 5th International Conference on Distance Learning and Education IPCSIT 12. 100104.

Chaurura, P \& Chuma, K. 2015. Virtual Laboratories- A Solution for Tertiary
Science Education in Botswana. European Journal of Logistics Purchasing and Supply Chain Management. 3(1), 29-43.

Clark, Ted. M dan Julia M. Chamberlain. 2014. "Use of a PhET Interactive Simulation in General Chemistry Laboratory: Models of the Hydrogen Atom". Journal of Chemical Education, 91(8).

Fahruddin. 2016. Pengaruh Model Pembelajaran Kooperatif terhadap Hasil Belajar Kognitif Ditinjau dari Kemampuan Akademik Mahasiswa. Jurnal Penelitian Pendidikan IPA JPPIPA, 2(1), 2016. 1-9. doi: 10.29303/jppipa.v2i1.27

Gunawan, G. A. 2017. Virtual Laboratory to Improve Students' Problem-Solving Skills On Electricity Concept. Jurnal Pendidikan IPA Indonesia JPII. 6 (2), 2017. 257-264.

Khairunnisak, 2018. Peningkatan Pemahaman konsep dan Motivasi Belajar Siswa Melalui Simulasi Physic Education Technology (Phet). Jurnal Penelitian Pendidikan IPA JPPIPA. 4(2), 2018. 7-12. doi: 10.29303/jppipa.v4i2.109

Masril, Hidayati \& Yenni Darvina. 2018. The Development of Virtual Laboratory Using ICT for Physics in Senior High School. IOP Conference Series: Materials Science and Engineering 335 (1), 012069.

Masril, Hidayati \& Yenni Darvina. 2019 Penerapan Discovery Learning Berbantuan Virtual Laboratory Untuk Meningkatkan Kompetensi Fisika Siswa SMA. Jurnal Penelitian Pendidikan IPA JPPIPA. 5(1), 2019. 18-26. doi: 10.29303/jppipa.v5i1.160

Moore, Emily B, Julia M. Chamberlain, Robert Parson, dan Katherine K. Perkins. 2014. PhET Interactive Simulations: Transformative Tools for Teaching Chemistry. Journal of Chemical Education, 91(8), 1191-1197

Prastowo, Andi. 2011. Panduan Kreatif Membuat Bahan Ajar Inovatif. Yogyakarta: Diva Press.

Sugiyono. (2012). Metode Penelitian Kuantitatif, Kualitatif dan $R \& D$. Bandung: Alfabeta.

Susilawati. 2015. Pengembangan Buku Ajar Astronomi Berbasis Self Regulated Learning Sebagai Upaya Memotivasi Mahasiswa untuk Belajar Mandiri. Jurnal Penelitian Pendidikan IPA JPPIPA. 1(2), $2015 \quad$ 110-117. doi: $\underline{10.29303 / j p p i p a . v 1 i 2.25}$ 